\title{
A Lecture in Medical Physiology- PowerPoint versus Chalkboard
}

\author{
Rekha Prabhu', Kirtana M Pai ${ }^{2}$, Girish Prabhu', Shrilatha ${ }^{3}$
}

\begin{abstract}
Background and objectives: Various teaching methodologies have been utilized in medical education, chalk board once was a staple of classrooms, but PowerPoints are now standard in most medical schools. Objectives were a) to understand the student perspective on the use of different teaching modes in Medical Physiology b) to rate the effectiveness of lectures by different modes of teaching.

Method: A lecture in physiology was delivered to two batches of First year of Bachelor of Medicine and Bachelor of surgery (I MBBS) students. For one batch of students the lecture was delivered using PowerPoint, for the second batch of students, the same content was taught using a chalk board. A multiple choice question examination was conducted before (Pre-test) and after (Post-test) delivering the lecture. The students were given a questionnaire to choose between the chalkboard (CB) or PowerPoint (PPT) method for the various attributes.
\end{abstract}

Results: It was observed that students scored better in the post-test examination, and no significant difference in score was seen between PowerPoint or chalkboard. According to the students, the attributes "clarity of words" (67\%), "stress on important points" (52\%) and "summarizations" (80\%) were best dealt with PowerPoint and chalk board based lectures gave better "clarity of concepts" $(71 \%)$, "learning to draw diagrams" (67\%), "better understanding of the subject" $(59 \%)$, "easier note taking" (55\%). The preferred method for delivering lectures was CB $(51 \%)$.

Conclusion: Lectures could be improved by utilizing a combination of both chalkboard and PowerPoint, as they each have their own advantages.

Keywords: teaching media, undergraduate students, medical education.

\section{Introduction}

Teaching in medical schools has undergone a dramatic change. Various teaching methodologies have been utilized in medical education, which is an active area of educational research (Flores-Mateo \& Argimon, 2007).Technology moves fast and creates many new applications. The chalkboard was once a staple of school classrooms.

\footnotetext{
${ }^{1}$ School of Medicine, Taylor's University, Malaysia

${ }^{2}$ Department of Physiology, Kasturba Medical College, Manipal University, Manipal

${ }^{3}$ Department of Physiology, Bangalore Medical College, Bangalore

Corresponding author:

Dr Rekha Prabhu, Lecturer, School of Medicine

Taylor's University, No. 1 Jalan Taylor's 47500 Subang

Jaya, Selangor Darul Ehsan, Malaysia

E-mail: rekha.prabhu@taylors.edu.my
}

Teaching with the chalkboard engages learners actively and the learner is more attentive to what the teacher is discussing, writing and illustrating on the board. In the chalkboard method, student easily makes a summary in his or her own words of the main thrust of the session, concentrates and tries to annotate this in relation to previous learning and possible future application, this may happen in chalk board method only because teacher easily facilitates the students to discuss, write, think and understand the core information in the class room (Meo, 2008). Active engagement of students increases their ability to think and understand. The students are also able to cope with the speed of the teacher with regard to content and illustrations. The learner makes a summary in his or her own words about the topic of discussion, concentrates and integrates with the contents of previous classes and possible future learning (Meo, 2008; Baxi et al., 2009). 
The traditional chalk board (CB) teaching has given way to PowerPoint presentations (PPT) and video tapes. PowerPoint teaching aid is said to be useful in larger groups (50 to 100) and enhances visual quality of text and figures. It also enables the inclusion of animated material. However, if PowerPoint presentations are not used appropriately, it will serve more as a means of mapping and directing the flow of a classroom discussion on a topic than as a means of presenting the materials themselves (David \& James, 2004). The presentation may involve too many words on a slide, making information indiscernible. Too much information may result in decreased eye to eye contact, which hinders communication. The student may end up focusing on graphics or fancy fonts and colours rather than course content or classroom discussion (McDonald, 2004).

Most institutions follow traditional curricula which are discipline based and basic sciences are taught in the first year. Basic sciences include preclinical subjects, Anatomy, Physiology and Biochemistry. Each discipline follows its own sequence. Learning outcomes are not clearly defined and individual lecturer decides about the content coverage.

We were interested in knowing the preferred teaching method of physiology among firstyear medical students. This will assist in the development of appropriate learning approaches. To achieve this goal, we designed a questionnaire to understand the students' perspective on the use of two modes of teaching at our institution. We also tested students before and after the lectures with two different audio-visual aids (PPT or CB) to observe the differences in learning.

\section{Methods}

This study was conducted in Kasturba Medical College, Manipal University, India which offers Bachelor of Medicine and Bachelor of Surgery program (MBBS), wherein the students undergo training in Anatomy, Physiology and Biochemistry in their first year. The curriculum includes didactic lectures, tutorials and practicals. The 250 students admitted into the first year are divided into 2 batches of 125 each for the didactic lecture sessions. The entry criteria for students are through the entrance examination. The selected students are divided into the two batches randomly. The study was conducted after both the batches of students had undergone the first continuous assessment (CA) exam in basic science subjects. The average score between the two batches of students in the Physiology Paper was comparable.

A lecture on Renal Physiology (Long term regulation of Blood Pressure) of one hour was delivered by the same lecturer to the two batches of first year MBBS students. For one batch of students the lecture was delivered using PowerPoint, for the second batch of students the chalkboard was used to present the same contents as the previous lecture. The lecture provided the students with a review of the renin-angiotensin-aldosterone mechanism in the regulation of blood pressure and sequential events taking place inside the human body to return blood pressure back to normal following increased intake of salt. The sequence of events in regulation of blood pressure was presented with flow chart and diagrams to both batches. Students of both batches were allowed to take down notes during the lecture. Single best multiple choice question examinations were conducted before (Pre-test) and after (Post-test) delivering the lecture on the same day for both batches. The duration of the test and the set of questions were same for both the batches of students.

We administered a questionnaire with various attributes to the students to determine their preferred methods of teaching. One hundred and forty six of the 250 students returned the complete questionnaire. Students were asked to choose the preferred method of teaching (CB or PPT) for each of the given attributes. Attributes listed included "flow of thought better", "stress on important points", "better summarization", "large number of facts can be given", "problem solving better", "clarity of words", "clarity of concepts", "note taking easier", "copying diagram easier", "promotes better understanding of the subject"," method of choice for delivering the lecture". The study was approved by the college ethical committee.

\section{Analysis}

The Pre- and Post-test scores were compared using paired t test. Independent sample t test was used to analyse the differences of the pre and the post test scores. A p value of less than 0.001 was considered to be statistically significant. The number of students who preferred each mode of learning was divided by the total number of responses to determine the percentage of students in each category. The data were analysed using SPSS for windows version 15. 


\section{Results}

The results of the Pre- and Post-test assessment are summarized in Table 1. Out of the 125 students in each batch, 111 and 121 students were available for lectures with PPT and $C B$ respectively on the day of study. There was significant improvement in post test scores compared to that of pre test scores with power point as well as chalk board. (For PPT, mean increase $=2.43, \quad S D=1.95, \quad t=13.69$, $\mathrm{SE}=0.18$, 95\% Confidence Interval: 2.08 to 2.78, $\mathrm{p}<0.001$.For $\mathrm{CB}$, mean increase $=2.77$, $\mathrm{SD}=2.07, \mathrm{t}=14.09, \mathrm{SE}=0.2,95 \%$ Confidence Interval: 2.38 to $3.16, \mathrm{P}<0.001$.) The difference in the Pre and the Post test scores of both methods was not statistically significant $(p=0.193)$.
Table 2 shows that chalk board teaching was chosen by most students for the following attributes: clarity of concepts; flow of thought better; learning to draw diagrams; better understanding of the subject; note taking easier.

Table 2 further illustrates that PowerPoint teaching was chosen by most students for the following attributes: clarity of words; large number of facts given; stress on important points; summarize better.

The preferences for lecture delivery by PowerPoint or chalkboard were $51 \%$ and $49 \%$ respectively.

Table 1: Scores of the assessment with two teaching methods

\begin{tabular}{lcccc}
\hline & \multicolumn{2}{c}{ PowerPoint $(\mathbf{n}=121)$} & \multicolumn{2}{c}{ Chalk board( $\mathbf{n = 1 1 1})$} \\
\cline { 2 - 5 } Pre test score & mean & SD & mean & SD \\
\cline { 2 - 5 } Post test score & 5.12 & 1.79 & 5.26 & 2.38 \\
Difference of the pre \& post & 7.55 & 1.9 & 8.04 & 2.04 \\
test score & 2.43 & 1.95 & 2.77 & 2.07 \\
\hline
\end{tabular}

Table 2: Preferred choices of CB/PPT for various attributes

\begin{tabular}{lcccc}
\hline \multirow{2}{*}{ Attributes } & \multicolumn{2}{c}{ Chalk board } & \multicolumn{2}{c}{ PowerPoint } \\
& $\mathbf{n}$ & $\mathbf{( \% )}$ & $\mathbf{n}$ & (\%) \\
\hline 1.Flow of thought better & 91 & 64 & 51 & 36 \\
2.Stress on important points & 68 & 48 & 74 & 52 \\
3.Better summarization & 29 & 20 & 113 & 80 \\
4.Large number of facts can be given & 20 & 14 & 122 & 86 \\
5.Problem solving better & 44 & 55 & 36 & 45 \\
6.Clarity of words & 47 & 33 & 95 & 67 \\
7. Clarity of concepts & 103 & 71 & 43 & 29 \\
8. Note taking easier & 77 & 55 & 63 & 45 \\
9.Copying diagrams easier & 96 & 67 & 47 & 33 \\
10.Promotes better understanding of the subject & 79 & 59 & 54 & 41 \\
11.Methods of choice for delivering lecture & 70 & 51 & 66 & 49 \\
\hline
\end{tabular}

\section{Discussion}

The pre-test scores between the two groups (CB and PPT) not exhibiting statistically significant difference implies that both groups had uniform background information on the topic. There was significant improvement in post test scores compared to pre test scores with PPT aiding the lecture (Table 1). This is consistent with the study which showed significant cognitive gain after a traditional lecture with power point slides (Galvis et al., 2011). The same lecture topic when taught with $\mathrm{CB}$ also resulted in a significant improvement in scores from pre to post test.

The finding that the post test scores of PPT and $C B$ classes did not show any statistical significance suggests that the two methods are equally effective in helping students learn (Table 1). However this is contrary to results documented in different settings where students who participated in lectures supported by PPT had higher grades compared to CB (Erdremir, 2011; Seth, 2010). 
There was no clear preference shown by students for PPT or CB as a desirable teaching aid in the present study (Table 2). The student preference varies, according to a study in which the medical students preferred PowerPoint presentations, but the dental students preferred chalk and talk (Seth et al., 2010). In a study among B. Pharm final year students, out of the 100 students, 81 recommended chalk and talk to be continued as the teaching tool compared to Microsoft PowerPoint presentation (Vamshi et al., 2011).

One of the main features of PowerPoint is that it provides structure to a presentation. This aids in the order and pacing of the lecture (Hlynka \& Mason, 1998). In addition, accompanying lectures with PPT is a more efficient time management strategy than writing on a whiteboard or using transparencies (Daniels, 1999). This could be the reason why a majority of students said that a larger number of facts could be given in a limited period of lecture. Also highlighting and bold fonts used for important parts draw students' attention. The students felt that PPT was better at stressing important points than $\mathrm{CB}$. However large number of slides and quick transition will result in students not able to cope with the speed of the teacher. This may prove that note taking easier with $\mathrm{CB}$ rather than PPT. Lectures aided by chalk board visuals are easier to take notes from because students can write what the professor writes on the board at the same time. Also, because there is usually more chalk board space than screen space, the visual would probably still be on the board for students to copy a few minutes later. The students thus felt note taking was easier with chalk board.

The sequence of events understood by the lecturer might be different from the pattern of flow on the slides in the power point presentation. Chalk board teaching has an advantage over this point where the teacher can be more flexible in deliverance of his lectures. Moreover, PowerPoint as a teaching tool constraints the presentation, as it is possible but not easy to omit a slide on the spot in a lecture. This makes the teacher less spontaneous (Hlynka \& Mason, 1998). The rigid structuring of the PPT can oversimplify complex ideas (Gallagher \& Reder, 2004$2005)$. This could be the reason why $59 \%$ of students said the chalk board allowed better understanding of the subject. Also, students quoted $\mathrm{CB}$ for better flow of thoughts and clarity of concepts.
Copying a diagram is always easier for a student if the teacher simultaneously traces it on the black board. The diagram on a slide in PPT neither gives the time nor the order of tracing for students to follow. Moreover, in PPT, teachers opt for flashy, eye catching diagrams, where as in the $C B$, teacher himself chooses a simplified style of drawing. $67 \%$ of students said copying diagrams were easier with $\mathrm{CB}$. We recommend that one switches to $\mathrm{CB}$ from PPT when the teacher feels that a particular figure or diagram should be reproduced by the student. Students are known to perform worse when PowerPoint slides are presented with pictures that are not relevant (Bartsch \& Cobern, 2003).

Many factors affect the clarity of words. $67 \%$ of the students felt that clarity of words was better with PPT. A teacher's pronunciation, loudness and accent may affect the clarity of words and most PPT presentations have important parts of lectures on its script (Thomas \& Raju, 2007).

\section{Conclusion}

The choice whether to use CB or PPT lies upon the teacher and also depends on the course design and topic of discussion. Any teaching aid or technology can only support, never replace for a carefully planned out learning activity. Technology is only a means of facilitating teaching and learning rather than an end in itself. Students enjoy the slow pace and interaction allowed by chalk board, and the clinical details a slide can provide. PPT and $C B$ have their advantages and disadvantages and that students would be best served by employing a combination of two methods. Students' interaction should be encouraged whatever the media used (Dhaliwal, 2007).

\section{Limitations}

The study was limited to one lecture and was brief in duration.

\section{Acknowledgements}

The authors wish to thank $\mathrm{Dr}$ Shreemathi Mayya, Associate Professor, Department of Statistics, Manipal University for the statistical analysis. 


\section{References}

Bartsch, R.A. \& Cobern, K.M. (2003).Effectiveness of PowerPoint presentation in lectures, Computers and Education 4 77-86.

Baxi, S.N., Shah, C.J., Parmar, R.D., Parmar, D. \& Tripathi, C.B. (2009) Students' perception of different teaching aids in a medical college, African Journal of Health Professions Education 1,1, p. 15.

Daniels, L. (1999) Introducing technology in the classroom: PowerPoint as a first step, Journal of Computing in Higher Education, 10, pp.42-56.

David, D.K. \& James, D.W. (2004) A case of PowerPoint as a faculty authoring system, Cell Biology Education, 3 pp. 155-161.

Dhaliwal, U.A. (2007) Prospective study of medical students' perspective of teaching-learning media: reiterating the importance of feedback, Journal of the Indian Medical Association, 105, 11, pp. 621-623, 636.

Erdremir, N. (2011) The impact of PowerPoint and Traditional Lecture on Students' Achievement in Physics, Journal of Turkish Science Education, 8, 3, pp. 176-189.

Flores-Mateo, G. \& Argimon, J.M. (2007)Evidence based practice in postgraduate healthcare education: a systematic review, BMC Health Services Research, 7, 119.

Gallagher, E.V. \& Reder, M. (2004-2005), Essays on Teaching Excellence - Toward the Best in the Academy, 16, 3, Available at http://teaching. uchicago.edu/oldsite/pod/04-05/Gallagher.htm
Galvis, A.T., Ishee, J.H. \& Schultz S (2011) A comparison of Computer Assisted Instruction \& Traditional Classroom to introduce the Occupational Adaptation Therapy, The International Journal of Allied Health Sciences and Practice, 3, pp. 1-6.

Hlynka, D. \& Mason, R. (1998) PowerPoint in the classroom: what is the point? Educational Technology, 38, pp. 45-48.

McDonald, K. (2004) Points of View: PowerPoint in the Classroom Examining PowerPointlessnes, Cell Biology Education, 3, 3, pp. 160-161.

Meo, S.A. (2008) Power of PowerPoint and role of chalkboard, Medical Teacher 30, 6, pp. 639641.

Thomas M, Raju, B.A. (2007) Are PowerPoint presentations fulfilling its purpose? South East Asian Journal of Medical Education, 1, 1, pp. 38-41.

Seth, V., Upadhyaya, P., Ahmad, M. \& Moghe, V. (2010) PowerPoint or chalk and talk: Perceptions of medical students versus dental students in a medical college in India, Advances in Medical Education and Practice, 1, pp. 11-16.

Vamshi, K.T., Datta, M.V., Kishan, Y.S.S., Aditya, V. \& Bhanuprakash, G. (2012)Comparative study on the teaching effectiveness of chalk and talk and Microsoft PowerPoint presentation from the student perspective, International Journal of Pharmacy and Pharmaceutical Sciences, 4, Suppl 1, pp. 191-193. 